\title{
Distribuição de líquido da Ponta de Pulverização com Indução De AR E JATo ExcênTrico AIUB 8502 sob Diferentes Condições ${ }^{1}$
}

\author{
Liquid Distribution of Air Induction and Off-Center Spray Nozzles under Different Conditions
}

\author{
VIANA, R.G. ${ }^{2}$, FERREIRA, L.R. ${ }^{3}$, ROSELL, J.R.. ${ }^{4}$, SOLANELLES, F. ${ }^{5}$, FILAT, A. ${ }^{5}$, MACHADO, M.S. ${ }^{6}$, \\ MACHADO, A.F.L. ${ }^{7}$ e SILVA, M.C.C. ${ }^{7}$
}

\begin{abstract}
RESUMO - Objetivou-se com este trabalho avaliar a distribuição de líquido da ponta de pulverização com indução de ar e jato excêntrico AIUB 8502 sob diferentes condições operacionais. Foram avaliados perfil individual, vazão, ângulo de abertura do jato, faixa de aplicação e distribuição volumétrica simulada de duas pontas AIUB 8502 nas pressões de trabalho de 200, 300, 400 e $500 \mathrm{kPa}$, altura de 30, 40 e $50 \mathrm{~cm}$ em relação ao alvo e espaçamento entre pontas de 30 a $100 \mathrm{~cm}$. Todas as análises foram realizadas seguindo a norma ISSO 5682-1, com algumas adaptações. A ponta apresentou distribuição de liquido excêntrica com um lado descontínuo e extremidade oposta excêntrica, com queda abrupta do volume de líquido. À medida que se aumentou a altura da barra e a pressão de trabalho, alongou-se o perfil do jato. O maior número de configurações uniformes foi obtido na altura de $50 \mathrm{~cm}$, decrescendo nas alturas de 40 e $30 \mathrm{~cm}$. A vazão e o ângulo do jato excêntrico aumentaram com o incremento na pressão, não havendo diferença entre o ângulo do jato descontínuo e o total entre as pressões de 400 e $500 \mathrm{kPa}$ e de 200 e $300 \mathrm{kPa}$.
\end{abstract}

Palavras-chave: barra, bico, pré-emergente, aplicação em faixa, mudas.

ABSTRACT - The objective of this work was to evaluate the liquid distribution of air induction and off-center AIUB 8502 spray nozzles under different operating conditions. Individual profile, spray nozzle outflow, spray angle, spray width and simulated distribution profile for two AIUB 8502 nozzles at working pressures of 200, 300, 400 and $500 \mathrm{kPa}$, height of 30,40 and $50 \mathrm{~cm}$ from the target and 30 to $100 \mathrm{~cm}$ spacing were evaluated. All the tests were performed following ISO 5682-1 with some adaptations. The nozzles presented an eccentric liquid distribution with a discontinuous side and eccentric opposing end, with sharp decrease in volume. Profile distribution increased with increased bar height and working pressure. The largest number of uniform configurations was obtained at the height of $50 \mathrm{~cm}$, decreasing at the heights of 40 and $30 \mathrm{~cm}$. Angle and flow rate of the off-center nozzle increased with increase in pressure, with no differences between discontinuous and total angles between 400 and $500 \mathrm{kPa}$, and 200 and $300 \mathrm{kPa}$ pressure ranges.

Keywords: bar, spray boom, pre-emergent, uniform application, seedlings.

\section{INTRODUÇÃO}

Uma das maneiras de maximizar a eficiência da aplicação e minimizar as perdas e os riscos de contaminação provocados por agrotóxicos pode ser a utilização de técnicas de aplicação adequadas a cada tipo de situação, com base nas características inerentes à interação de fatores climáticos, biológicos, econômicos e operacionais. Para isso, é necessário o emprego de todas as técnicas que proporcionem a correta colocação do produto

Recebido para publicação em 15.4.2009 e na forma revisada em 15.6.2010.

2 Engo-Agr ${ }^{\circ}$., M.Sc., Doutorando em Fitotecnia, Dep. de Fitotecnia, Universidade Federal de Viçosa - DFT/UFV, 36570-000 Viçosa-MG, Bolsista CNPq, <rafaelgomesviana@yahoo.com.br>; ${ }^{3}$ Prof. Associado, DFT/UFV; ${ }^{4}$ Prof. Doctor, Departament d'Enginyeria Agroforestal. Universitat de Lleida-España; ${ }^{5}$ Investigador Doctor, Centre de Mecanització Agrària, Departament d'Agricultura, Alimentació i Acció Rural, Generalitat de Catalunya; ${ }^{6}$ Mestrando do curso de Agronomia, UFV; ${ }^{7}$ Pós-doutorando em Fitotecnia. 
biologicamente ativo no alvo, em quantidade necessária, de forma econômica e com o mínimo de contaminação de outras áreas (Matuo et al., 2001).

Pulverizações hidráulicas são utilizadas na maioria das aplicações de agrotóxicos, devido à flexibilidade que oferecem em diversas situações (Teixeira, 1997). É essencial conhecer o comportamento dos componentes envolvidos na pulverização hidráulica - entre eles a ponta de pulverização, considerada a parte mais importante, por ser responsável pela formação e distribuição de gotas sobre o alvo (Matuo, 1990).

O sucesso na aplicação de agrotóxico depende de pontas de pulverização que propiciem um perfil de distribuição uniforme, espectro de gotas homogêneo e de tamanho adequado (Cunha, 2003).

A uniformidade na distribuição da calda aplicada ao longo da barra varia com as condições de montagem e de operação, entre elas: espaçamento entre pontas, altura da barra, ângulo de abertura do jato e pressão de trabalho (Perecin et al., 1999).

A uniformidade de distribuição preconizada pela norma UNE-EM 12761:2 (2002) estabelece que o coeficiente de variação (CV\%) da sobreposição de jatos seja menor que $7 \%$ quando utilizados altura, espaçamento e pressão recomendados pelo fabricante e de até $9 \%$ em configuração distinta. Valores acima podem indicar sobreposição exagerada ou deficiente, acarretando problemas no controle de plantas daninhas, pragas ou doenças em razão de falhas de sobreposição de jatos ou intoxicação de culturas, perdas financeiras e danos ao ambiente em sobreposição demasiada. São conhecidos diversos exemplos de intoxicação de culturas provocados diretamente por deriva de herbicidas não seletivos. Em eucalipto foram observados danos visuais e anatômicos nas folhas (Tuffi Santos et al., 2008) e na produção de madeira (Tuffi Santos et al., 2007) provocados pela deriva de glyphosate. Rigoli et al. (2008) observaram danos no desenvolvimento e crescimento em plântulas de beterraba e cenoura, bem como efeito similar em tomate (Figueredo et al., 2007) e em maracujazeiroamarelo (Wagner Júnior et al., 2008), todos por efeito da deriva de glyphosate.
O conhecimento das características de distribuição volumétrica pode favorecer também a indicação de espaçamentos entre pontas que promovam maior faixa de aplicação, menor volume de calda e maior rendimento operacional, sem, contudo, reduzir a eficiência de controle. Esses fatos foram evidenciados por diversos autores, que indicam espaçamentos, pressões de trabalho e altura da ponta em relação ao alvo que favoreçam maior rendimento operacional e eficiência de controle (Freitas et al., 2005; Cunha et al., 2006; Ferreira et al., 2007; Viana et al., 2007, 2009).

Além da distribuição do agrotóxico, outras características são do suma importância para correta aplicação de produto, como espectro de gotas, vazão, ângulo de abertura e formato do jato. Um dos problemas que podem ser minimizados é a deriva de calda. As pontas de pulverização com ar induzido promovem a inclusão de ar na gota produzida, formando uma grande partícula, a qual se deposita no alvo com maior eficiência, tendo o inconveniente de não cobri-lo em grandes proporções, o que não é limitante para herbicidas aplicados em préemergência ou herbicidas sistêmicos em pósemergência (Viana et al., 2007). Etheridge et al. (1999) observaram maior diâmetro da mediana volumétrica e menor porcentagem de gotas com diâmetro inferior a $250 \mu \mathrm{m}$ para as pontas de pulverização com indução de ar, comparado a pontas de jato plano convencionais, indicando as pontas com ar induzido para redução de deriva de herbicidas não seletivos.

Pontas de pulverização de jato excêntrico são aquelas que possuem formato de jato direcionado somente para um lado, de maneira que produza uma extremidade de jato descontínuo ou uniforme, a qual exige sobreposição com outro jato uniforme e outra extremidade com queda abrupta de deposição de calda, podendo ser recomendada para uso em diversas situações, como no final de barras de pulverização, durante tratamento de culturas sensiveis e de áreas não alvo, e na aplicação em faixa ou dirigida a culturas, como a aplicação de herbicidas pré-emergentes sobre mudas de frutíferas e espécies florestais e aplicações subfoliares.

A ponta de pulverização AIUB 8502 possui as características de jato excêntrico, combinadas com a indução de ar, com maior 
tamanho de gota e menor propensão à deriva. É indicada para aplicação em pós-emergência de herbicidas sistêmicos ou em pré-emergência das plantas daninhas e adubos foliares, os quais não necessitam de grande cobertura do alvo. Como exemplo prático de utilização dessa ponta pode ser citada a aplicação de herbicidas pré-emergentes sobre linhas de plantio de eucalipto, café e frutíferas. O espaçamento entre pontas, a pressão de trabalho, a altura da ponta em relação ao alvo e a faixa de aplicação não são conhecidos para uma pulverização criteriosa nessas situações. Assim, objetivou-se neste trabalho avaliar a distribuição de líquido, o ângulo de saída do jato e a vazão da ponta de pulverização de jato excêntrico AIUB 8502 sob diferentes condições operacionais.

\section{MATERIAL E MÉTODOS}

As avaliações foram realizadas nos laboratórios do Centre de Mecanitzaciò Agrària de la Genaralitat de Catalunya, no campus Universitário da Universitat de Lleida-Espanha. Foram utilizadas cinco pontas de pulverização AIUB 8502 novas, sendo cada unidade considerada uma repetição.

Os perfis de distribuição foram determinados utilizando-se uma barra porta-bicos sobre uma mesa de teste para pontas de pulverização hidráulica, composta por canaletas metálicas, separadas entre si em $5 \mathrm{~cm}$ e com provetas com capacidade para $300 \mathrm{~mL}$, alinhadas a cada canaleta. A mesa foi construída de acordo com a norma ISO 5682-1 (ISO, 1996).

A ponta foi instalada isoladamente no centro da mesa, de modo que o jato fosse lançado na posição vertical por um tempo suficiente para que pelo menos uma proveta tivesse $90 \%$ do seu volume completado. A cada repetição foi realizada a média de três avaliações, e os volumes coletados foram transformados em porcentagem do volume aplicado, com posterior plotagem dos dados em gráfico (Microsoft Excel). Foram utilizadas as pressões de 200, 300, 400 e $500 \mathrm{kPa}$ e as alturas de 30,40 e $50 \mathrm{~cm}$ em relação à mesa.

Com base nos volumes médios coletados em cada tratamento, foram simulados o padrão médio de distribuição volumétrica ao longo de uma barra de pulverização com duas pontas AIUB 8502, com o lado descontínuo sobrepondo-se ao centro da barra, e espaçamento entre pontas de $30,40,50,60,70,80$, 90 e $100 \mathrm{~cm}$, de maneira a indicar a melhor relação altura, espaçamento entre pontas e pressão de trabalho para aplicação em faixa. Foi calculado o Coeficiente de Variação (CV\%) da sobreposição dos jatos, sendo os valores abaixo de $7 \%$ considerados uniformes e indicados para aplicação. A faixa de deposição analisada na distribuição volumétrica situou-se entre os dois maiores volumes coletados de cada ponta; no caso de CV\% menores que $7 \%$, a faixa foi sendo aumentada até onde fosse uniforme.

A vazão da ponta foi mensurada nas pressões de 200, 300, 400 e $500 \mathrm{kPa}$ em um caudalímetro eletromagnético (Digitron +), dotado de um sistema hidráulico, dispositivo eletrônico de restrição de pressão e analisador de vazão em tempo real, conforme realizado por Sztachó-Pekáry (2006). A pressão de $300 \mathrm{kPa}$ serviu de referência para verificar se a vazão da ponta estava de acordo com as normas de codificação por cores estabelecidas pela ISO 5682-1 (1996).

A determinação do ângulo do jato foi feita por meio de imagens frontais da ponta de pulverização operando nas pressões de 200, 300,400 e $500 \mathrm{kPa}$, obtidas com câmera digital com resolução de 6.1 megapixels (MP) e com a função flash ativada. As imagens foram analisadas por meio do software Image Tool versão 3.0. O ângulo de abertura foi medido a partir das projeções delimitadas tangencialmente às bordas do jato, sendo mensurado o ângulo do jato descontínuo, excêntrico; o ângulo total das pontas foi calculado pela soma dos ângulos normal e descontínuo.

A análise da distribuição volumétrica das pontas de pulverização foi feita pelo cálculo do coeficiente de variação (CV \%) da sobreposição dos jatos. Os dados de vazão e ângulo do jato foram submetidos à ANOVA, e as médias, comparadas pelo teste de Tukey a $5 \%$ de probabilidade. As análises foram realizadas no software SAEG versão 8.0 (UFV, 2000).

\section{RESULTADOS E DISCUSSÃO}

A ponta de pulverização AIUB 8502 possui perfil de distribuição com maior deposição de 
líquido em uma das extremidades e queda abrupta para o lado excêntrico, apresentando deposição descontínua na extremidade oposta (Figura 1), fato esse relacionado ao ângulo de saída do jato pulverizado, sendo maior no lado descontínuo e menor no lado excêntrico
(Tabela 2). Houve alongamento do perfil individual com o aumento da altura da barra em relação ao alvo e da pressão de trabalho, acarretando maior faixa de deposição e menor porcentagem de volume aplicado em todo o perfil, independentemente da vazão (Figura 1).
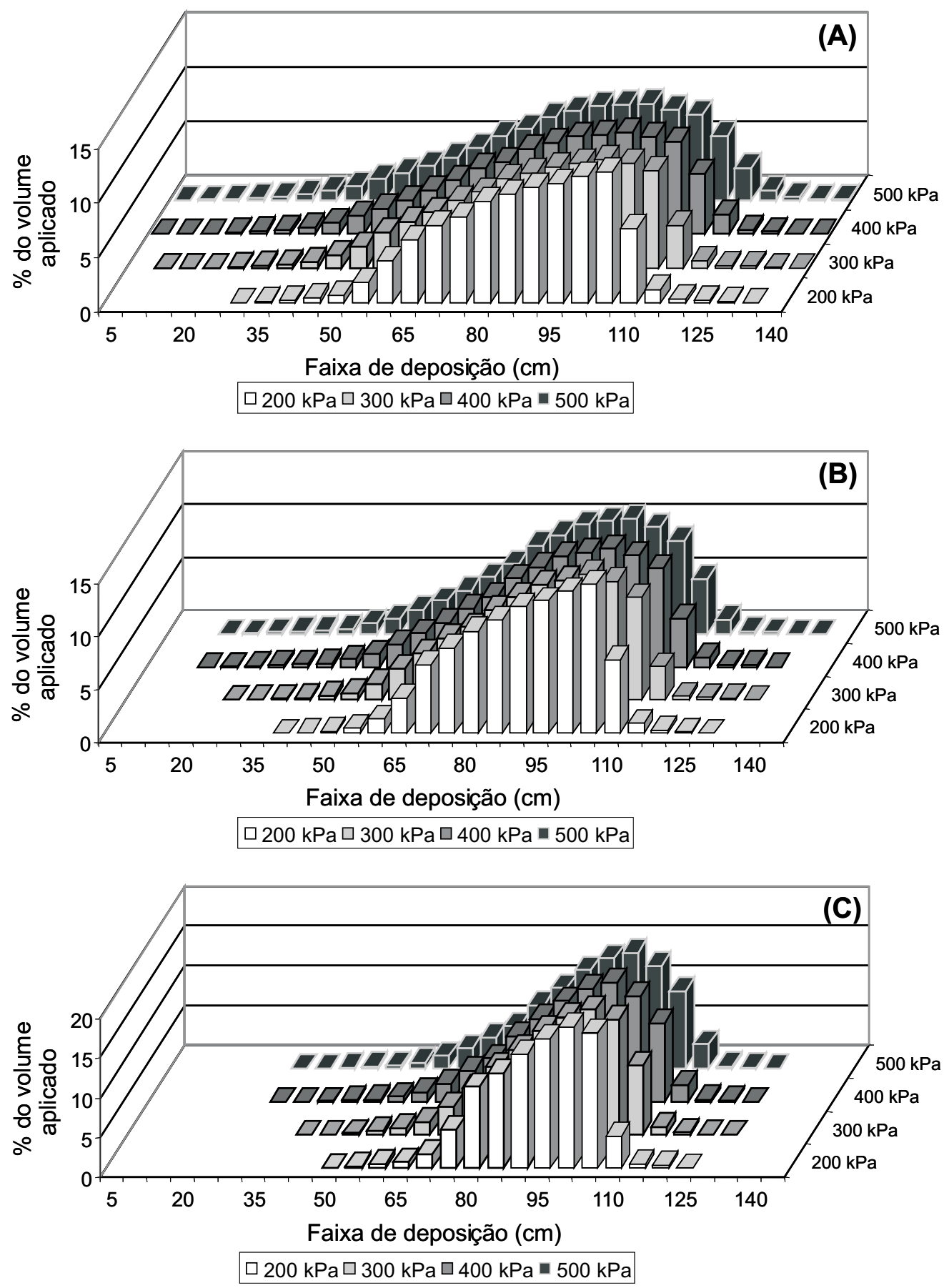

Figura 1 - Perfis de distribuição de líquido da ponta de pulverização AIUB 8502 operando nas pressões de 200, 300, 400 e 500 kPa, a $50 \mathrm{~cm}(\mathrm{~A}), 40 \mathrm{~cm}(\mathrm{~B})$ e $30 \mathrm{~cm}(\mathrm{C})$ de altura em relação ao alvo. 
A concentração de líquido se torna maior e a faixa de deposição menor à medida que se reduz a altura e a pressão de trabalho. Resultados semelhantes foram observados por Viana et al. (2007), avaliando características técnicas de pontas de pulverização de jato plano com indução de ar.

O perfil observado para a ponta AIUB 8502 permite recomendar a utilização no final de barras de pulverização. Permite também a sobreposição de duas pontas AIUB 8502, realizando uma distribuição volumétrica uniforme para aplicação de herbicidas em faixa na linha ou entrelinha de plantios.

Tabela 1 - Coeficiente de variação (CV\%) do perfil de distribuição e faixa de deposição central avaliada da ponta de pulverização AIUB 8502 em diferentes pressões de trabalho, alturas da barra e espaçamentos entre pontas na barra de pulverização

\begin{tabular}{|c|c|c|c|c|c|c|c|}
\hline \multirow{3}{*}{$\begin{array}{c}\text { Pressão } \\
(\mathrm{kPa})\end{array}$} & \multirow{3}{*}{$\begin{array}{l}\text { Espaçamento } \\
\text { entre pontas } \\
\quad(\mathrm{cm})\end{array}$} & \multicolumn{6}{|c|}{ Altura da barra $(\mathrm{cm})$} \\
\hline & & \multicolumn{3}{|c|}{$\begin{array}{c}\text { Coeficiente de } \\
\text { Variação (CV\%)* }\end{array}$} & \multicolumn{3}{|c|}{$\begin{array}{l}\text { Faixa de deposição } \\
\text { central avaliada } \\
(\mathrm{cm})\end{array}$} \\
\hline & & 30 & 40 & 50 & 30 & 40 & 50 \\
\hline \multirow{8}{*}{200} & 30 & 8 & 11 & 5 & 40 & 50 & 45 \\
\hline & 40 & 7 & 13 & 9 & 50 & 60 & 50 \\
\hline & 50 & 29 & 9 & 13 & 60 & 60 & 60 \\
\hline & 60 & 48 & 7 & 8 & 70 & 70 & 80 \\
\hline & 70 & 67 & 21 & 7 & 80 & 90 & 90 \\
\hline & 80 & 76 & 36 & 16 & 90 & 100 & 100 \\
\hline & 90 & 87 & 49 & 29 & 100 & 110 & 110 \\
\hline & 100 & 97 & 63 & 41 & 110 & 120 & 120 \\
\hline \multirow{8}{*}{300} & 30 & $\overline{4}$ & 10 & 7 & 40 & 50 & 40 \\
\hline & 40 & 5 & 11 & 7 & 50 & 60 & 60 \\
\hline & 50 & 19 & 6 & 7 & 50 & 60 & 60 \\
\hline & 60 & 34 & 5 & 7 & 70 & 90 & 70 \\
\hline & 70 & 51 & 12 & 4 & 80 & 90 & 100 \\
\hline & 80 & 64 & 25 & 7 & 90 & 100 & 100 \\
\hline & 90 & 75 & 38 & 17 & 100 & 100 & 100 \\
\hline & 100 & 85 & 52 & 28 & 110 & 110 & 110 \\
\hline \multirow{8}{*}{400} & 30 & $\overline{3}$ & 10 & 5 & 40 & 50 & 40 \\
\hline & 40 & 5 & 7 & 7 & 50 & 50 & 50 \\
\hline & 50 & 17 & 6 & 7 & 50 & 70 & 60 \\
\hline & 60 & 32 & 6 & 6 & 70 & 90 & 70 \\
\hline & 70 & 46 & 10 & 4 & 80 & 90 & 100 \\
\hline & 80 & 59 & 22 & 5 & 90 & 90 & 110 \\
\hline & 90 & 79 & 30 & 14 & 100 & 110 & 100 \\
\hline & 100 & 80 & 33 & 24 & 110 & 110 & 110 \\
\hline \multirow{8}{*}{500} & 30 & 7 & 11 & 9 & 50 & 50 & 40 \\
\hline & 40 & 9 & 7 & 8 & 50 & 50 & 40 \\
\hline & 50 & 13 & 6 & 7 & 60 & 70 & 60 \\
\hline & 60 & 8 & 7 & 7 & 80 & 90 & 70 \\
\hline & 70 & 7 & 10 & 4 & 90 & 100 & 100 \\
\hline & 80 & 16 & 19 & 7 & 90 & 100 & 110 \\
\hline & 90 & 29 & 30 & 12 & 100 & 110 & 110 \\
\hline & 100 & 42 & 41 & 21 & 110 & 110 & 110 \\
\hline
\end{tabular}

* Valores abaixo de 7\% são considerados satisfatórios.
As melhores configurações, utilizando duas pontas de pulverização, estão apresentadas na Tabela 2. De maneira geral, espaçamentos entre pontas muito distantes ou muito próximas promovem maior coeficiente de variação, devido à falta ou excesso de deposição de líquido na parte central, conforme observado na Figura 2M e N. A implicação prática dessa informação é que, com espaçamento muito grande (Figura $2 \mathrm{M}$ ), poderá ocorrer menor ou ausência de controle de plantas daninhas na faixa central, e em espaçamentos menores (Figura $2 \mathrm{~N}$ ) podem ocorrer perdas financeiras e intoxicação de culturas por doses superiores na região central.

Obteve-se maior número de configurações uniformes na altura de $50 \mathrm{~cm}$, seguida pela de 40 e $30 \mathrm{~cm}$ (Tabela 1), em razão da maior faixa de aplicação individual proporcionada pelas pontas nessa condição (Figura 1).

A pressão de trabalho também influenciou as distribuições, chamando a atenção a pressão de $200 \mathrm{kPa}$ com menores configurações uniformes. Essa pressão de trabalho proporciona menor faixa de aplicação e ângulo total do jato aspergido (Tabelas 1 e 2), o que reduz a sobreposição de jatos e provoca depressão de líquido na região central, aumentando assim o CV\% da sobreposição dos jatos. Outra condição que implica menor faixa e menor ângulo do jato aspergido é o maior tamanho de gotas proporcionado nessa pressão. Pontas de pulverização com indução de ar proporcionam gotas grandes devido à entrada de ar no seu interior, o que acarreta perda de carga cinética e menor fragmentação da calda. Pressões inferiores a $200 \mathrm{kPa}$ para pontas de jato plano com indução de ar para aplicação em área total não devem ser recomendadas, pois os perfis apresentados, nesse caso, são uniformes e não indicados para aplicação com sobreposição (Viana et al., 2007; Cunha \& Ruas, 2006).

Trabalhando na pressão de $500 \mathrm{kPa}$, observou-se perfil uniforme na altura de $50 \mathrm{~cm}$, com espaçamento variando entre 50 e $80 \mathrm{~cm}$; na altura de $40 \mathrm{~cm}$, com espaçamento entre 40 e $60 \mathrm{~cm}$; e na altura de $30 \mathrm{~cm}$, com espaçamentos de 30 e $70 \mathrm{~cm}$ (Tabela 1).

Quando se reduziu a pressão para $400 \mathrm{kPa}$, foi observado perfil uniforme na altura de $50 \mathrm{~cm}$, com espaçamento entre 30 e $80 \mathrm{~cm}$; na 
altura de $40 \mathrm{~cm}$, com espaçamento entre $40 \mathrm{e}$ $60 \mathrm{~cm}$; e na altura de $30 \mathrm{~cm}$, com espaçamentos de 30 e $40 \mathrm{~cm}$.

A pressão de $300 \mathrm{kPa}$ proporcionou melhores configurações na altura de $50 \mathrm{~cm}$, com espaçamento de 30 a $80 \mathrm{~cm}$; na altura de $40 \mathrm{~cm}$, com espaçamento entre pontas de
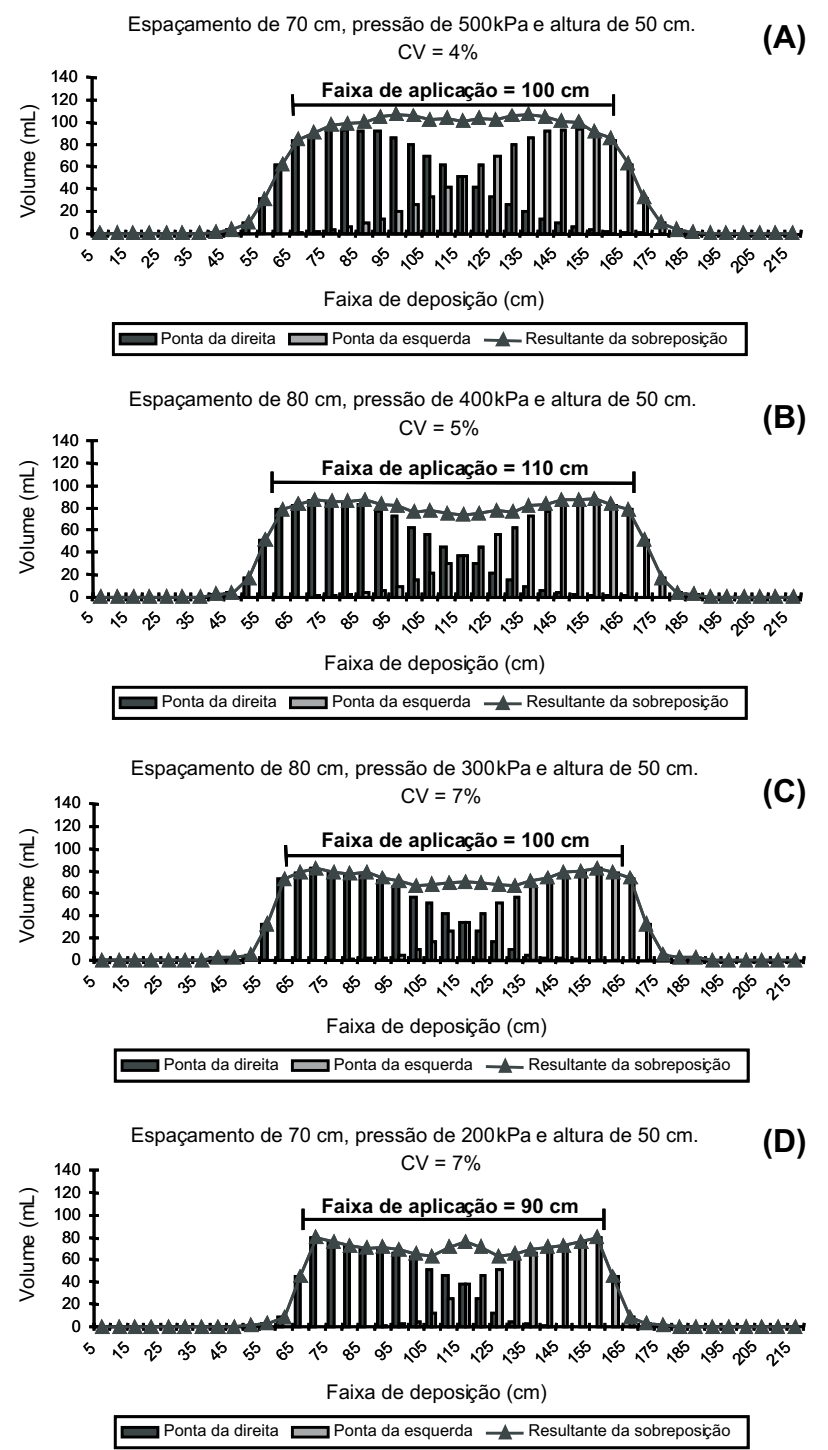

(D)

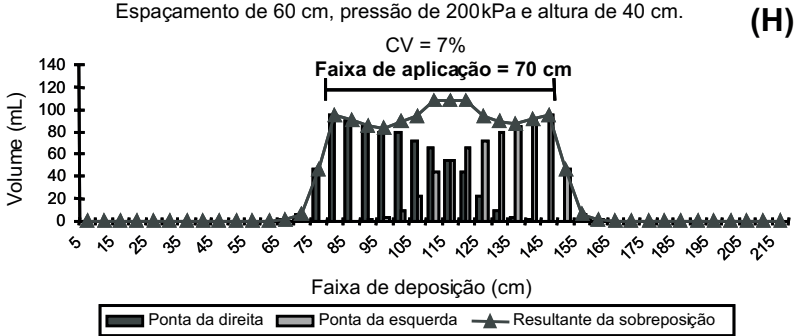

Continua...

50 e $60 \mathrm{~cm}$; e na altura de $30 \mathrm{~cm}$, com espaçamento entre pontas de 30 e $40 \mathrm{~cm}$.

A pressão de $200 \mathrm{kPa}$ apresentou menor número de configurações, sendo indicado somente os espaçamentos de 70,60 e $40 \mathrm{~cm}$, nas alturas de 50,40 e $30 \mathrm{~cm}$, respectivamente.
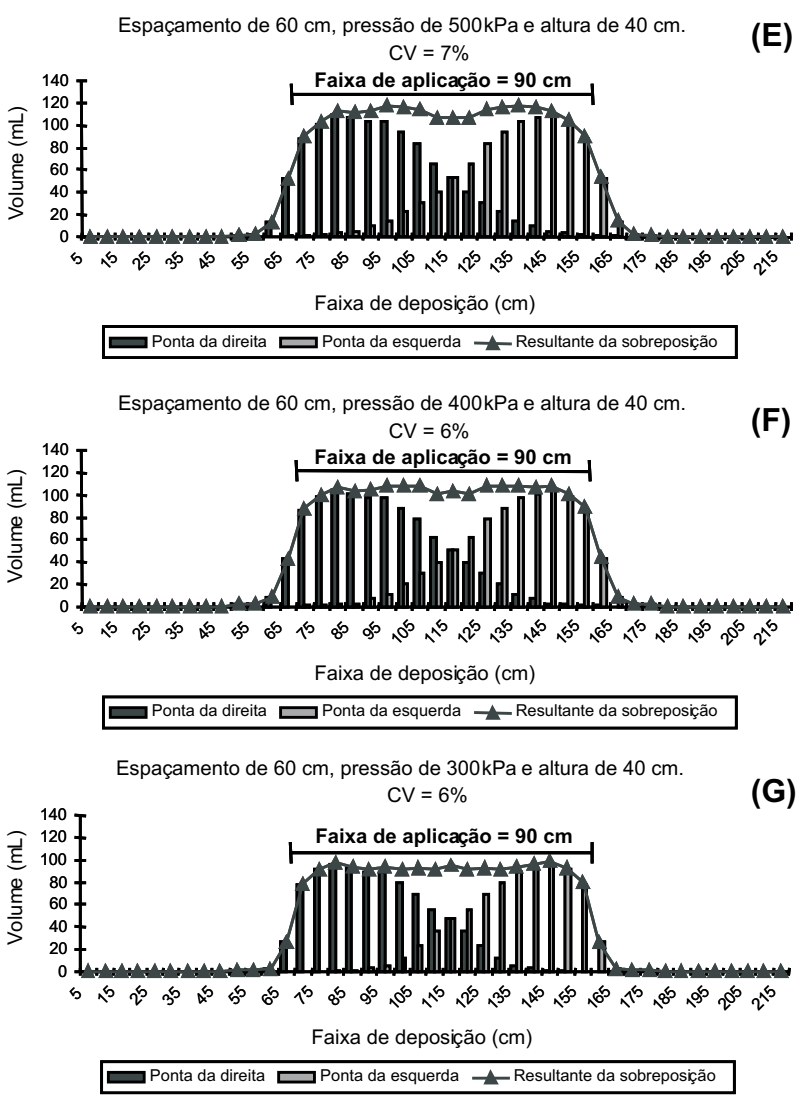

(G)

Figura 2 - Distribuição volumétrica de duas pontas de pulverização AIUB 8502 simulando uma barra de pulverização sob diferentes condições operacionais. Espaçamento de $70 \mathrm{~cm}$, pressão de $500 \mathrm{kPa}$ e altura de $50 \mathrm{~cm}$ (A); espaçamento de $80 \mathrm{~cm}$, pressão de $400 \mathrm{kPa}$ e altura de $50 \mathrm{~cm}$ (B); espaçamento de $80 \mathrm{~cm}$, pressão de $300 \mathrm{kPa}$ e altura de $50 \mathrm{~cm}(\mathrm{C})$; espaçamento de $70 \mathrm{~cm}$, pressão de $200 \mathrm{kPa}$ e altura de $50 \mathrm{~cm}$ (D); espaçamento de $60 \mathrm{~cm}$, pressão de $500 \mathrm{kPa}$ e altura de $40 \mathrm{~cm}$ (E); espaçamento de $60 \mathrm{~cm}$, pressão de $400 \mathrm{kPa}$ e altura de $40 \mathrm{~cm}(\mathrm{~F})$; espaçamento de $60 \mathrm{~cm}$, pressão de $300 \mathrm{kPa}$ e altura de $40 \mathrm{~cm}$ (G); espaçamento de $60 \mathrm{~cm}$, pressão de $200 \mathrm{kPa}$ e altura de $40 \mathrm{~cm}(\mathrm{H})$; espaçamento de $30 \mathrm{~cm}$, pressão de $500 \mathrm{kPa}$ e altura de $30 \mathrm{~cm}$ (I); espaçamento de $40 \mathrm{~cm}$, pressão de $400 \mathrm{kPa}$ e altura de $30 \mathrm{~cm}(\mathrm{~J})$; espaçamento de $40 \mathrm{~cm}$, pressão de $300 \mathrm{kPa}$ e altura de $30 \mathrm{~cm}(\mathrm{~K})$; espaçamento de $40 \mathrm{~cm}$, pressão de $200 \mathrm{kPa}$ e altura de $30 \mathrm{~cm}(\mathrm{~L})$; espaçamento de $100 \mathrm{~cm}$, pressão de $300 \mathrm{kPa}$ e altura de $50 \mathrm{~cm}(\mathrm{M})$; espaçamento de $30 \mathrm{~cm}$, pressão de $500 \mathrm{kPa}$ e altura de $40 \mathrm{~cm}(\mathrm{~N})$. 

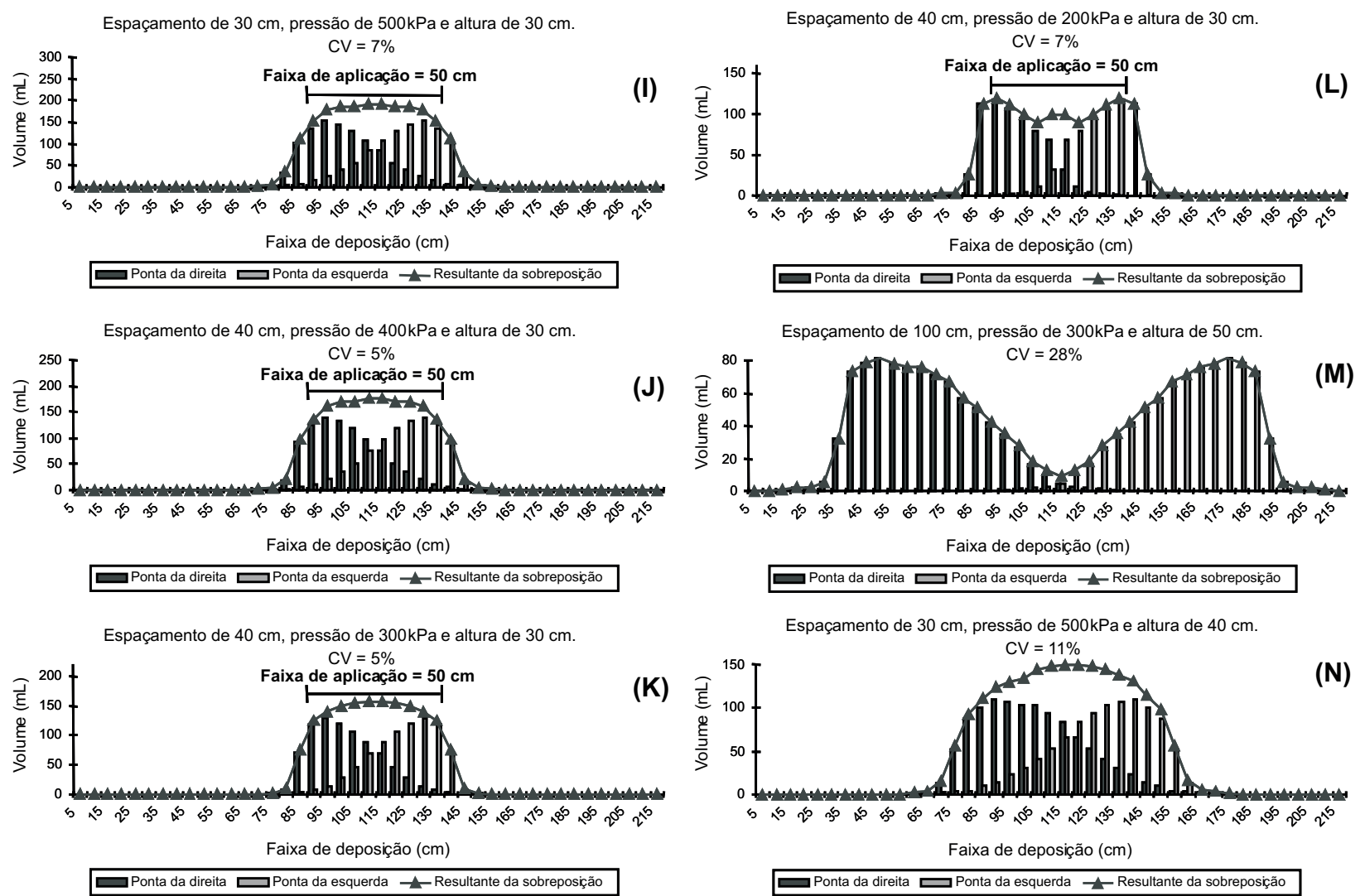

Figura 2, continuação.

Tabela 2 - Médias de vazão e de ângulo de abertura do jato considerando o lado normal e excêntrico em relação ao plano vertical, operando nas diferentes pressões

\begin{tabular}{|c|c|c|c|c|}
\hline \multirow{2}{*}{$\begin{array}{c}\text { Pressão } \\
(\mathrm{kPa})\end{array}$} & \multirow{2}{*}{$\begin{array}{c}\text { Vazão } \\
\left(\mathrm{L} \mathrm{min}^{-1}\right)\end{array}$} & \multicolumn{3}{|c|}{ Ângulo de abertura do jato $\left(^{\circ}\right)$} \\
\cline { 3 - 5 } & & $\begin{array}{c}\text { Lado } \\
\text { descontínuo }\end{array}$ & $\begin{array}{c}\text { Lado } \\
\text { excêntrico }\end{array}$ & Total \\
\hline 200 & $0,64 \mathrm{D}$ & $50,53 \mathrm{C}$ & $13,81 \mathrm{D}$ & $64,34 \mathrm{C}$ \\
\hline 300 & $0,78 \mathrm{C}$ & $54,11 \mathrm{BC}$ & $16,96 \mathrm{C}$ & $71,07 \mathrm{~B}$ \\
\hline 400 & $0,90 \mathrm{~B}$ & $58,34 \mathrm{AB}$ & $19,15 \mathrm{~B}$ & $77,49 \mathrm{~A}$ \\
\hline 500 & $1,00 \mathrm{~A}$ & $58,99 \mathrm{~A}$ & $20,76 \mathrm{~A}$ & $79,75 \mathrm{~A}$ \\
\hline
\end{tabular}

Médias seguidas da mesma letra na coluna não diferem entre si pelo teste de Tukey a $5 \%$ de probabilidade.

Para aplicações de herbicidas em faixa em culturas perenes, como eucalipto e café, geralmente se indica uma faixa superior a $1 \mathrm{~m}$ sobre as mudas. Essa faixa é conseguida de maneira uniforme nas pressões de 500 e $400 \mathrm{kPa}$, nos espaçamentos de 70 e $80 \mathrm{~cm}$ (Figura 2A e B), e $300 \mathrm{kPa}$, no espaçamento de $80 \mathrm{~cm}$ (Figura 2C). Os maiores espaçamentos obtidos com uniformidade de distribuição podem ser visualizados na Figura 2.

Maior espaçamento entre pontas promovem menor volume de calda gasto por área, sendo esse fator adequado ao aumento do rendimento operacional, sem, contudo, reduzir a eficiência de controle de plantas daninhas. Freitas et al. (2005) indicam espaçamento entre pontas de até 1,2 $\mathrm{m}$ utilizando a ponta de pulverização de jato plano e impacto TT11002, com gasto de volume de calda abaixo de $100 \mathrm{~L} \mathrm{ha}^{-1}$ com pulverizadores costais. Da mesma maneira, Viana et al. (2009) indicam espaçamento de até $1 \mathrm{~m}$ para ponta de pulverização de duplo leque TTJ60-11002 para redução no volume de calda na altura de $50 \mathrm{~cm}$ ou espaçamento de $50 \mathrm{~cm}$ na altura de $30 \mathrm{~cm}$ para redução da deriva de gotas.

$\mathrm{O}$ incremento na pressão promoveu aumento na vazão das pontas, conforme visualizado na Tabela 2. A recomendação do 
fabricante de classificar a ponta de pulverização em 2 galões min $^{-1}$ (cor amarela), assim como as vazões indicadas nas pressões avaliadas, estão corretas, conforme as normas de classificação na norma ISO 5682-1 (1996).

A pressão de trabalho também influenciou o ângulo de abertura do jato (Tabela 2). Analisando a abertura do lado descontínuo, observou-se que nas pressões de 500 e $400 \mathrm{kPa}$ não houve diferença, o que resultou em faixas de aplicação de deposição de calda semelhantes no alvo, conforme observado na Tabela 1. Situação semelhante foi constatada por Viana et al. (2007) e Ferreira et al. (2007) com pontas de pulverização de jato plano, em que o incremento na pressão aumentou o ângulo de saída do jato e a faixa de deposição proporcionada pelas pontas de pulverização.

O ângulo do jato excêntrico aumentou com o incremento na pressão (Tabela 2), sendo esse fato desfavorável, pois busca-se com esse tipo de ponta que o ângulo do lado excêntrico seja uniforme e pequeno, de maneira que haja menor deposição de calda possivel e, dessa maneira, evitar danos a culturas sensiveis e em áreas não alvo.

O ângulo de abertura total foi influenciado pelo ângulo de abertura descontínuo, já que não houve diferença entre as pressões de 400 e $500 \mathrm{kPa}$, as quais foram superiores às de 200 e $300 \mathrm{kPa}$. Maior ângulo indica maior faixa de aplicação e, desse modo, maior sobreposição com outro jato, sendo possível maior espaçamento entre pontas e menor volume de calda gasto por área aplicada. Em contrapartida, maior ângulo de jato pode ser prejudicial em espaçamentos menores, ocasionando acúmulo de calda na região central e possiveis perdas financeiras e intoxicação de culturas, devido ao aumento da dose recomendada.

A ponta de pulverização AIUB 8502 apresenta perfil de distribuição excêntrico com espaçamento entre pontas adequado à pulverização uniforme em diferentes configurações e com faixas de aplicação de até $1,10 \mathrm{~m}$. A vazão e o ângulo de pulverização aumentaram com o incremento na pressão. A configuração mais adequada à aplicação de uma faixa de $1 \mathrm{~m}$ é com pressão de $300 \mathrm{kPa}$, altura de $50 \mathrm{~cm}$ e espaçamento entre pontas de $80 \mathrm{~cm}$.

\section{AGRADECIMENTOS}

Ao CNPq, pela concessão de bolsa de estudos ao primeiro autor; à CAPES, pela concessão de bolsa para realização das atividades no exterior; ao sr. Jaap Boot, representando a empresa Spray System Co., pela doação das pontas de pulverização; e ao Centre de Mecanitzaciò Agrària.

\section{LITERATURA CITADA}

CUNHA, J. P. A. R. Tecnologia de aplicação do chlorothalonil no controle de doenças do feijoeiro. 2003. $81 \mathrm{f}$. Tese (Doutorado em Mecanização Agrícola) Universidade Federal de Viçosa, Viçosa, MG, 2003.

CUNHA, J. P. A. R.; RUAS, R. A. A. Uniformidade de distribuição de pontas de pulverização de jato plano duplo com indução de ar. Pesq. Agropec. Trop., v. 36, n. 1, p. 61-66, 2006.

ETHERIDGE, R. E.; WOMAC, A. R.; MUELLER, T. C. Characterization of the spray droplet spectra and patterns of four venturi-type drift reduction nozzles. Weed Technol., v. 13, p. 765-770, 1999.

FIGUEREDO, S. S. et al. Influência de doses reduzidas do glyphosate no tomateiro (Lycopersicon esculentum Mill.). Planta Daninha, v. 25, n. 3, p. 849-857, 2007.

FERREIRA, M. C. et al. Fatores qualitativos da ponta de energia hidráulica ADGA 110015 para pulverização agrícola. Eng. Agríc., v. 27, n. 2, p. 471-478, 2007.

FREITAS, F. C. L. et al. Distribuição volumétrica de pontas de pulverização turbo teejet 11002 em diferentes condições operacionais. Planta Daninha, v. 23, n. 1, p. 161-167, 2005.

INTERNATIONAL ORGANIZATION FOR STANDARDIZATION - ISO. Equipment for crop protection - Spraying equipment - Part 2: test methods for agricultural sprayers. Geneva: 1996. $13 \mathrm{p}$. (ISO 5682/1)

MATUO, T. et al. Tecnologia de aplicação e equipamentos. In: CURSO DE PROTEÇÃ̃ DE PLANTAS. Módulo 2. Brasília: ABEAS; Viçosa, MG: UFV, 2001. 85 p.

MATUO, T. Técnicas de aplicação de defensivos agrícolas. Jaboticabal: FUNEP, 1990. 140 p.

PERECIN, D. et al. Avaliação do desempenho de bicos para aplicação de herbicidas. Planta Daninha, v. 17, n. 1, p. $83-94,1999$ 
RIGOLI, R. P. et al. Resposta de plantas de beterraba (Beta vulgaris) e de cenoura (Daucus carota) à deriva simulada de glyphosate. Planta Daninha, v. 26, n. 2, p. 451-456, 2008.

SZTACHÓ-PEKÁRY, I. Influence of fan nozzle tip orifice wear on spray pattern. Progress Agric. Eng. Sci., v. 2, n. 1, p. $35-49,2006$.

TEIXEIRA, M. M. Influencia del volumen de caldo y de la uniformidad de distribución transversal sobre la eficacia de la pulverización hidráulica. 1997. 310 f. Tese (Doutorado em Agronomia) - Universidad Politécnica de Madrid, Madrid, 1997.

TUFFI SANTOS, L. D. et al. Crescimento do eucalipto sob efeito da deriva de glyphosate. Planta Daninha, v. 25, n. 1, p. 133-137, 2007.

TUFFI SANTOS, L. D. et al. Danos visuais e anatômicos causados pelo glyphosate em folhas de Eucalyptus grandis. Planta Daninha, v. 26, n. 1, p. 9-16, 2008.
UNE-EM. Maquinaria agrícola y forestal - Pulverizadores y distribuidores de fertilizantes líquidos. Protección medioambiental. Parte 2: Pulverizadores hidráulicos de barras para cultivos bajos. 2002. (UNE-EM 907: 1997)

UNIVERSIDADE FEDERAL DE VIÇOSA - UFV. SAEG Sistemas de Análises Estatísticas e Genéticas. (Versão 8.0). Viçosa, MG: 2000.

VIANA, R. G. et al. Deposición transversal de líquido de las boquillas de doble abanico TTJ60-11004 y TTJ60-11002 en distintas condiciones operacionales. Planta Daninha, v. 27, n. 2, p. 397-403, 2009.

VIANA, R. G. et al. Características técnicas de pontas de pulverização LA-1JC e SR-1. Planta Daninha, v. 25, n. 1, p. 211-218, 2007.

WAGNER JÚNIOR, A. et al. Deriva simulada de formulações comerciais de glyphosate sobre maracujazeiro-amarelo.

Planta Daninha, v. 26, n. 3, p. 677-683, 2008. 